\title{
An integrated platform for energy-saving operation in urban rail transit
}

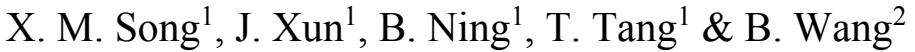 \\ ${ }^{I}$ The State Key Laboratory of Rail Traffic Control and Safety, \\ Beijing Jiaotong University, Beijing \\ ${ }^{2}$ School of Electrical Engineering, Beijing Jiaotong University, Beijing
}

\begin{abstract}
As regenerative braking technology is widely used in urban rail transit system, there is an interest to find an optimization method for energy-saving train operation based on the information from traction power supply. To study such method, this paper introduces an integrated hardware-in-loop simulation platform, which has a model integrating train operation control and traction power supply. In this model, the train operation optimal control model provides train operation information for a traction power supply model, and the traction power supply model generates data of voltage and current based on the characteristics of traction power supply, which is needed by the train operation optimal strategy. Based on the model, an energy-saving optimal algorithm for train control is proposed. The algorithm adds third-rail voltage into inputs. When the third-rail voltage rises, the algorithm will judge whether nearby trains under control of the same substation meet the conditions to accelerate and will adjust train operation mode (accelerate) if possible to realize the maximum utilization of regenerative braking energy. In order to ensure schedule adherence, the proposed model adjusts running time in the next inter-station. The feasibility and effectiveness of the proposed method are verified on the integrated hardware-in-loop simulation platform based on field test of Yizhuang line, Beijing Subway. The result shows that the proposed algorithm has little effect on punctuality rate and it can save $7.34 \%$ on energy for traction at the most.
\end{abstract}

Keywords: train control, energy-saving, real-time control. 


\section{Introduction}

As the development of urban rail transit, more and more attention is attracted to the energy-saving technology for train operation. RTS 2012 sets four goals of development in railway: customer satisfaction, capacity increase, cost reduction and carbon reduction [1]. Research carries out for the realization of these goals gradually. Especially, research on regenerative braking energy becomes the hot topic in this field.

At present, one of studies on the use of regenerative braking energy focuses on off-line schedule optimization, which is to maximize overlap time of accelerating and braking section of successive trains under control of the same substation. Gordon and Lehrer [2] proposed a method to avoid unnecessary braking, to make full use of recovery energy by coordinating the order of train's acceleration and brake. Nag and Pal [3] established a model for timetable optimization based on the use of recovery energy. A cooperative scheduling model, which synchronized the accelerating and braking times of successive trains such that the recovery energy from the braking train can simultaneously be used by the accelerating train, was originally proposed in [4-5] based on the position of substations on Beijing Yizhuang line. Although studies in this area can theoretically be able to make good use of regenerative braking energy, utilization results of energy-saving timetables is much lower just because of the fact that it's unable to ensure trains follow the schedule strictly.

Other recent developments in this field concentrate on real-time control for improving the usage of regenerative braking energy. Xun et al. [6] proposed an approach for coordinating trains in fully automatic operation system by modifying running time between adjacent stations to improve the usage of regenerative energy. Albrecht [7] searched for an optimal distribution of a train's running time reserve along its ride by using genetic algorithm and dynamic programming. But they ignore the impact of third-rail voltage on generation of regenerative braking energy.

The third-rail voltage will rise when train is braking. That will determine whether electric brake can be adopted. If the voltage is too high, regenerative braking current will be limited and regenerative braking energy will reduce. Or even, if the voltage exceeds the limit voltage, electric brake will be cut off and there will be no regenerative braking energy generated. The model integrating train operation control and traction power supply, proposed in this article, takes the interaction of train braking and third-rail voltage and current into account. In order to achieve the best use of regenerative braking energy, we analyze how to get optimal operating strategy while considering the variation of third-rail voltage, based on Beijing Yizhuang line.

The paper is organized as follows: In Section 2, the use strategy of regenerative braking for Yizhuang Line, Beijing Subway is introduced. Then a model integrating train operation control and traction power supply is proposed in Section 3. And the accuracy of the model is verified in Section 4 based on the field test data in Yizhuang Line. In Section 5, the efficiency and energy-saving effect of energy-saving optimal algorithm is simulated on the integrated platform. 


\section{Strategy of using regenerative braking for Yizhuang Line}

Braking system of trains which run on Yizhuang Line includes electric brake and air brake. Electric brake is the first choice when train begins to brake. When electric brake is used, train stops getting power from the third-rail. And at this time, the traction motor works as a generator to convert kinetic energy to electrical energy. This part of energy feedback to third-rail, which is the regenerative braking energy (fig. 1).

In Yizhuang Line, electric brake is used prior and air break is as auxiliary brake. When train brakes, brake force needed by trailer car is firstly provided by electric brake and the third-rail voltage will rise. If the voltage exceeds $980 \mathrm{~V}$, signal to remove electric brake will start. Then regenerative braking force is reduced, and air brake force will generally increase to meet the required brake force. When third-rail voltage reaches $1050 \mathrm{~V}$, electric brake will be completely cut off and brake force needed by train will be totally provided by air brake. This is one situation that regenerative brake is totally disabled, the other is that train speed reduces to $6 \mathrm{~km} / \mathrm{h}$. If train speed reduces to $6 \mathrm{~km} / \mathrm{h}$, signal to remove electric brake will also start. And electric brake will gradually reduce and air brake will increase in $400 \mathrm{~ms}$ approximately. Electric brake will be replaced by air brake in the end.

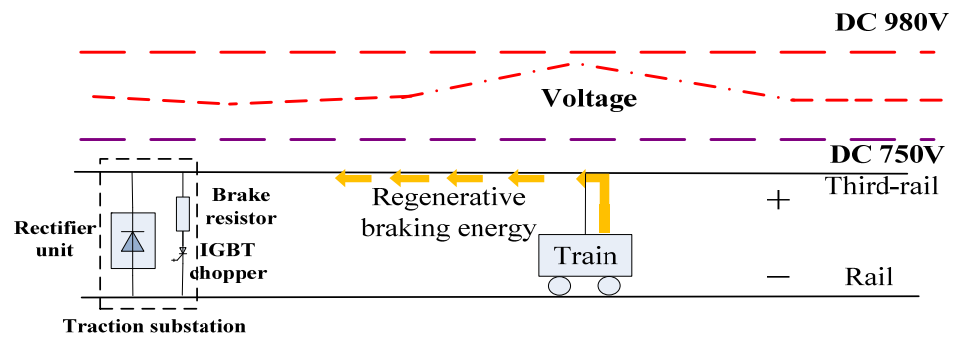

Figure 1: Diagrammatic sketch for regenerative braking in Yizhuang Line.

\section{A model integrating train operation control and traction power supply}

Integrated hardware-in-loop simulation platform includes traction power supply model and train operation control model. Traction power supply model includes traction substations and trains. It simulates the changes of third-rail voltage and current while the train is running. Train optimal control model provides dynamic information of train for traction power supply system, and traction power supply model feedback third-rail voltage and current to train optimal control model, based on which the optimal control model generates optimal operation strategies. In this paper, simulation platform includes two trains, one is a practicality model and the other is a software model. 


\subsection{Train optimal control model}

This model generates energy-saving speed profile between two stations and realtime adjustment strategy about train operation according to the third-rail voltage feedback by traction power supply model.

\subsubsection{Calculation of objective speed profile}

When the train arrived at the station, train control model will adjust running time between the stopped station and the next station, according to the actual arrival time at this station and planned arrival time at next station, to prevent trains deviating from schedule too much. This model calculates the most energy-efficient speed profile on the premise of guaranteeing the safe and stable operation of the train. Optimal speed profile includes four operation conditions "maximum traction, cruising, coasting, maximum braking" [8-9]. To simplify the calculation, conditions for speed profile used in this paper just includes traction, coasting and braking, as shown in fig. 2 :

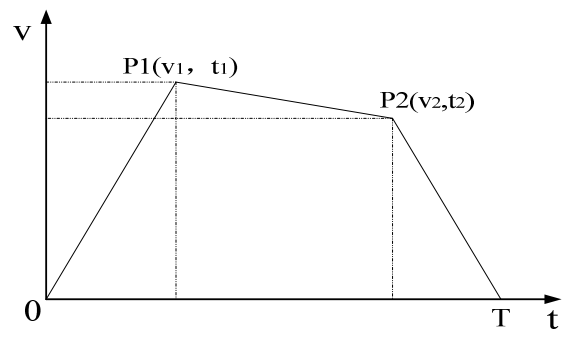

Figure 2: Optimal speed profile for a single train.

The sum of traction time, coasting time, braking time is equal to the running time between stations, and the sum of the running distance under the three operation conditions is equal to the distance between stations. Train's speed profile can be obtained according to the following formula while not consider the effect of limit speed and slope:

$$
\begin{gathered}
\frac{v_{1}}{a_{t}}+\frac{v_{1}-v_{2}}{a_{c}}+\frac{v_{2}}{a_{b}}=T \\
\frac{v_{1}^{2}}{2 a_{t}}+\frac{v_{1}^{2}-v_{2}^{2}}{2 a_{c}}+\frac{v_{2}^{2}}{2 a_{b}}=S
\end{gathered}
$$

with constrains: $v_{1} \leq v_{\max }, T \geq T_{\min }$.

- $a_{t}$ means the acceleration rate during acceleration;

- $a_{c}$ means the acceleration rate during coasting;

- $a_{b}$ means the deceleration rate during braking;

- $\quad T$ means the travel time;

- $\quad S$ means the distance between two stations.

Based on eqns. (1) and (2), we can determine the two transfer points P1 and P2. 


\subsubsection{Adjustment of train operation strategy}

During a train's running process between stations, the model will determine whether the train's running state can be adjusted to absorb regenerative braking energy when the third-rail voltage is higher than the rated voltage.

As shown in fig. 3, Train $i+1$ and $i$ are in the same power supply section. When Train $i$ is braking, the model judges Train $i+1$ 's operation condition.

If Train $i+1$ is accelerating, it can absorb regenerative braking energy produced by Train $i$. The absorbed energy of Train $i$ from the substation will be less than the total energy needed for traction.

If Train $i+1$ is under coasting condition, the model will determine whether the train can accelerate at the moment. At the same time, safety should be considered. If Train $i+1$ can accelerate, it will absorb the regenerative braking energy generated by Train $i$. As a result, Train $i+1$ will arrive at the next stop in advance. Train operation control model will extend the running time of Train $i+l$ between the stopped station and the next station according to the actual arrival time at this station and planned arrival time at next station. As a consequence, energy consumption will be reduced.

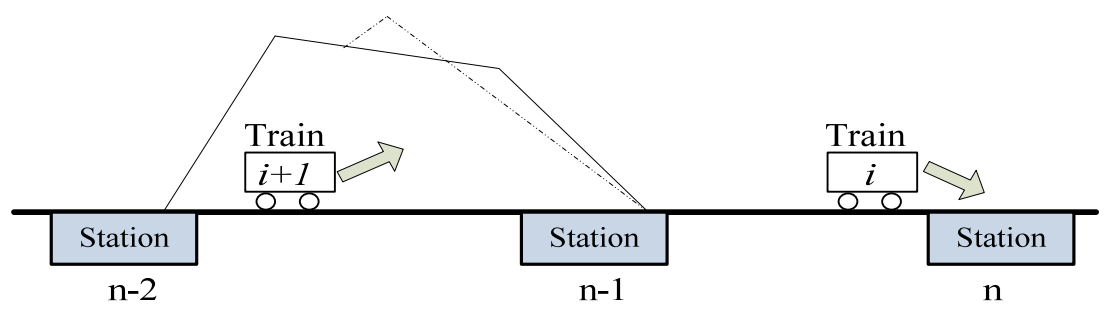

Figure 3: Scenario of utilization of regenerative braking energy.

In this paper, the coasting train must meet the requirement from headway, stopping accuracy, and limit speed, then it can use regenerative braking energy to accelerate. The requirement can be written as follows:

$$
\left\{\begin{array}{l}
t_{n-1}^{i-1}-t_{n-1}^{i}>H_{\min } \\
v_{i+\Delta t}^{t+\Delta t}<\sqrt{2 a_{b}\left(S^{n-1}-S_{i+1}^{t}\right)} \\
v_{i+1}^{t+\Delta t}<v_{\text {limit }}
\end{array}\right.
$$

- $S_{i}^{t}$ means coordinate of the $\mathrm{i}+1$ th train at time $\mathrm{t}$;

- $S^{n-1}$ means position of station $\mathrm{i}+1$;

- $v_{i+1}^{t}$ means the $\mathrm{i}+1$ th train speed at time $\mathrm{t}$;

- $\quad v_{\text {limit }}$ represents the limit speed;

- $t_{n-1}^{i}$ means arrive time of train $\mathrm{i}$ at station $\mathrm{n}-1$.

If the regenerative braking energy makes the Train $i$ 's third-rail voltage rise to $950 \mathrm{~V}$, and Train $i+1$ meet the conditions to accelerate, then Train $i+1$ can accelerate with the maximum traction force. The braking resistor will absorb the 
remained part of energy. If not, acceleration of train $i+1$ is determined by the regenerative braking energy. Namely,

$$
\left\{\begin{array}{l}
v_{i+1}^{t+\Delta t}=v_{i+1}^{t}+\frac{F}{m} \Delta t, \quad \text { if } F v_{i+1}^{t}<P_{r} \\
v_{i+1}^{t+\Delta t}=v_{i+1}^{t}+\frac{P_{r}}{v_{i+1}^{t} m} \Delta t, \text { if } F v_{i+1}^{t}>P_{r}
\end{array}\right.
$$

where $F$ means the maximum traction force; $P_{r}$ means the regenerative braking energy produced in unit time.

\subsection{Model for traction power supply}

\subsubsection{Model for traction substation}

Substation outputs energy for traction trains. If there's a train braking in the power supply section and there's no train to absorb regenerative braking energy produced by the braking train, voltage on both sides of substation will rise. When the voltage on both sides of substation is higher than substation's output voltage, diode will be blocked and substations cannot output energy. The ground absorption equipment will be turned on and absorb regenerative braking energy when the third-rail voltage reaches its threshold voltage. In order to simulate unidirectivity of current across the substation, a switch is added to the substation model. When the current is positive, the switch is on, and when the current is negative, the switch is off.

\subsubsection{Hardware model for a single train}

The integrated hardware-in-loop simulation platform using train load simulation platform to simulate the train system. One small power motor is traction motor, and the other one is load motor to simulate running resistance. Traction motor is controlled by MYWAY power electronic experimental platform, and load motor is controlled by DSPACE control platform. The practicality model of the train is shown in fig. 4 .

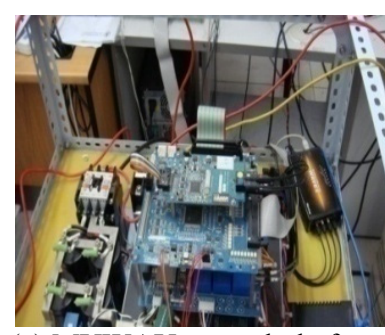

(a) MYWAY control platform

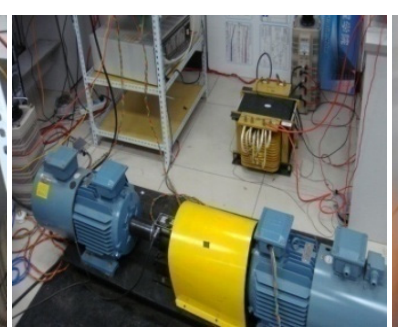

(b) Motor

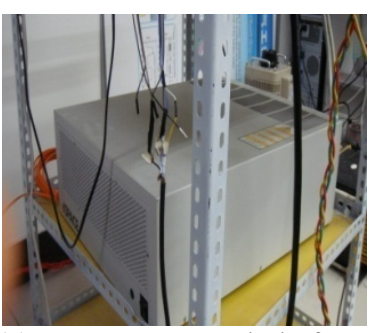

(c) DSPACE control platform

Figure 4: Practicality model for train. 


\section{Simulation}

\subsection{Flow chart}

The flow chart of integrated model is shown in fig. 5. The optimization control is triggered when third-rail voltage is higher than the rated voltage value.

If the adjacent train of the braking train is accelerating, then it can use regenerative braking energy. And the lack part is still provided by substation. If the adjacent train is coasting, and it meets the conditions of acceleration, then train optimal control model will adjust train running states to accelerate to absorb regenerative braking energy. Acceleration is determined by regenerative braking energy power and maximum acceleration rate. The adjacent train's actual arrival time at the next station will be earlier than the planned arrival time in this case. When adjacent train arrives at the next station, train operation control model will contract actual arrival time and planned arrival time of the train, and extend the running time between the stopped station and the next station according to the actual arrival time at this station and planned arrival time at next station. Train operation control model will calculate optimal speed profile according to the new running time.

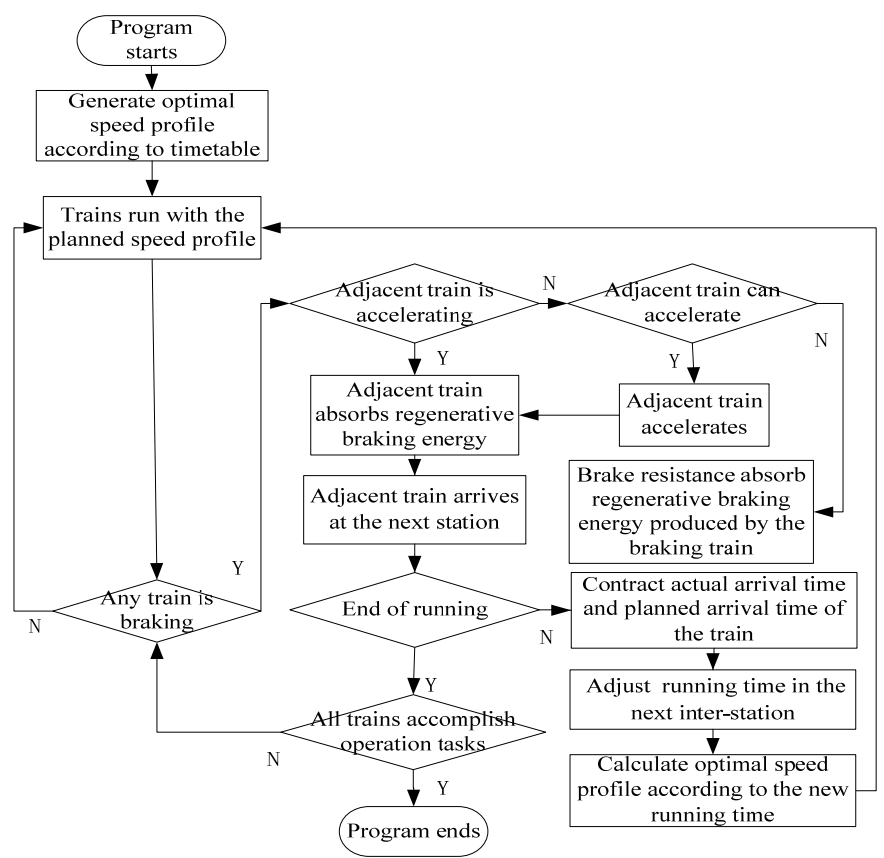

Figure 5: Flow chart of the proposed model. 


\subsection{Energy consumption calculation model}

In this paper, energy consumption of the train only includes the traction energy consumption, and energy consumption of the auxiliary equipment is not included. The effect of device efficiency of traction system, such as inverter efficiency, motor efficiency, and gear efficiency, should be considered while calculating the energy consumption of the train. If output traction and train speed is known, we can get the train traction power according to the flow of energy when the train is in traction.

$$
P=\frac{F \times v}{\eta_{G E A R} \times \eta_{M M} \times \eta_{I N V}}=I_{d c} \times U
$$

where $\eta_{I N V}$ indicates inverter efficiency, $\eta_{M M}$ refers to motor efficiency, $\eta_{G E A R}$ means gear transmission efficiency.

\subsection{Comparison of preliminary simulation data and field test data}

To verify the accuracy of the model in this paper, field test of Yizhuang Line was conducted. Yizhuang line is 23.23 kilometers long. As shown in fig. 6, the subway has 14 stations, running from Songjiazhuang Station to Yizhuang Railway Station. Field test of Yizhuang Line only includes Songjiazhuang, Xiaocun, Xiaohongmen and Jiugong four stations and 3 inter-stations between them. Test data mainly includes inter-station travel time, total energy consumption, traction energy consumption, train load and other statistical data and train dynamic data. The accuracy of the model is verified through the simulated energy consumption and the tested energy consumption based on the measured speed sequence of the train.

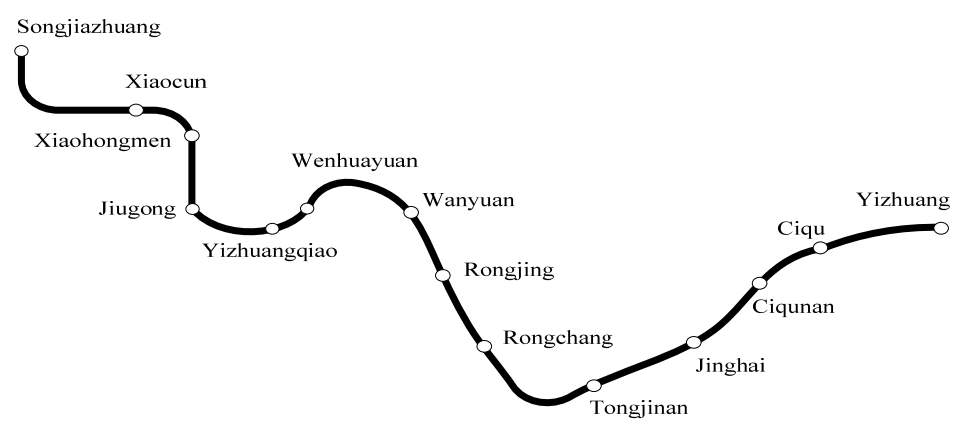

Figure 6: Graph of Yizhuang Line, Beijing Subway.

In Yizhuang Line, inverter efficiency is $92 \%$; motor efficiency is $93 \%$; gear transmission efficiency is $97 \%$.

Other parameters in the simulation are as follows:

- The dispatching headway at original station is 120 seconds;

- $\quad$ Train length is 120 meters;

- $\quad$ Safety distance is 40 meters; 
- Weight of train is 199 tons;

- The maximum acceleration rate is $1 \mathrm{~m} / \mathrm{s}^{2}$;

- The maximum deceleration rate is $1 \mathrm{~m} / \mathrm{s}^{2}$ for service brake and $1.2 \mathrm{~m} / \mathrm{s}^{2}$ for emergency brake;

- $\quad$ The rated third-rail voltage is $750 \mathrm{~V}$;

- Train load is the same as the field test data.

Table 1: Comparisons between simulation data and field test data.

\begin{tabular}{|c|c|c|c|c|c|c|}
\hline & \multirow[b]{2}{*}{$\begin{array}{c}\text { Train } \\
\text { load } \\
(t)\end{array}$} & \multirow[b]{2}{*}{$\begin{array}{c}\text { Travel } \\
\text { time } \\
(\mathrm{s})\end{array}$} & \multicolumn{2}{|c|}{ Field test data(kw.h) } & \multicolumn{2}{|c|}{ Simulated data (kw.h) } \\
\hline & & & $\begin{array}{c}\text { Traction } \\
\text { energy } \\
\text { consumption }\end{array}$ & $\begin{array}{c}\text { regenerative } \\
\text { braking } \\
\text { energy }\end{array}$ & $\begin{array}{c}\text { Traction } \\
\text { energy } \\
\text { consumption }\end{array}$ & $\begin{array}{c}\text { regenerative } \\
\text { braking } \\
\text { energy }\end{array}$ \\
\hline $\begin{array}{c}\text { Songjiazhuang } \\
\text { to Xiaocun }\end{array}$ & 50.97 & 198 & 28 & 15 & 23.60 & 13.53 \\
\hline $\begin{array}{c}\text { Xiaocun to } \\
\text { Xiaohongmen }\end{array}$ & 48.82 & 109 & 16 & 10 & 15.70 & 10.40 \\
\hline $\begin{array}{c}\text { Xiaohongmen } \\
\text { to Jiugong }\end{array}$ & 46.80 & 154 & 34 & 9 & 32.52 & 9.72 \\
\hline
\end{tabular}
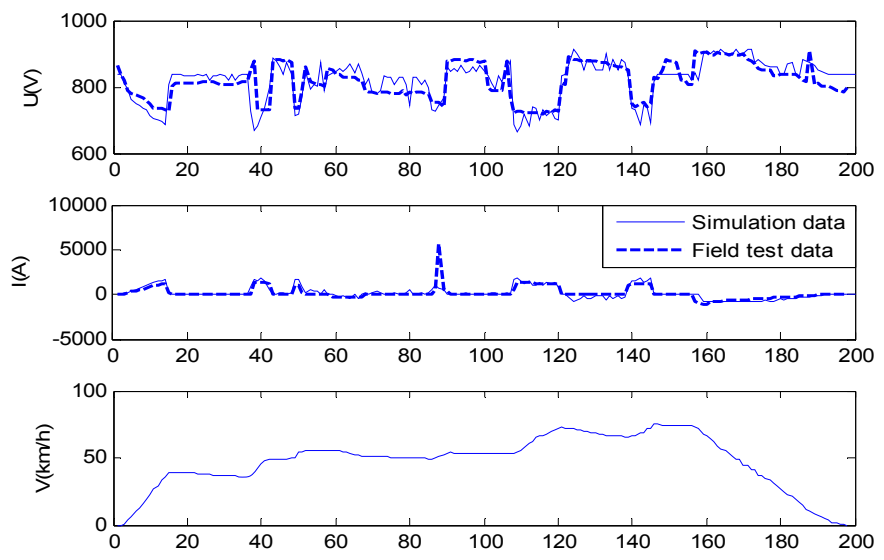

Figure 7: Comparison of voltage and current data.

Fig. 7 shows the simulated third-rail voltage and current curves based on the train's real speed sequence from Songjiahzuang to Jiugong. As the fig. 7 shows, when the train is accelerating, there's a positive current across the train. Voltage on both sides of the train decreases because of the increase of current provided by substation. When the train is braking, there is a reverse current and voltage on both sides of the train increases because of the energy feedback to third-rail. But the reverse current is not gradually increasing because of the current limiter. This is called the regenerative braking partial failure. Therefore, the actual generated regenerative braking energy is less than the decrease of kinetic energy of the train. Variation trends of simulation data are same as that of field test data in fig. 7. But 
there are some differences between them in the value of some points. In order to improve the accuracy of the model, the paper compares the simulation data and field test data, and then adjusts the simulation results based on the field test data.

\section{Discussion}

\subsection{Analysis on energy-saving effect}

This paper simulates two trains running from Songjiazhuang to Jiugong, via Xiaocun and Xiaohongmen. Among the four stations, Songjiazhuang, Xiaocun and Xiaohongmen belong to the same power supply section. Speed profile is calculated based on the calculation in Section 3.

The objective speed profile is calculated by train optimization control model. When there's no optimization, the train runs with the objective speed profile. Train operation adjustment isn't involved. The use of regenerative braking energy can exist when there are braking train and accelerating train in the same power supply section at the same time. And there's no use of regenerative braking energy (fig. 8 (a)). After joining the proposed optimal model, the train's operation state changed in order to use regenerative braking energy (fig. 8 (b)).

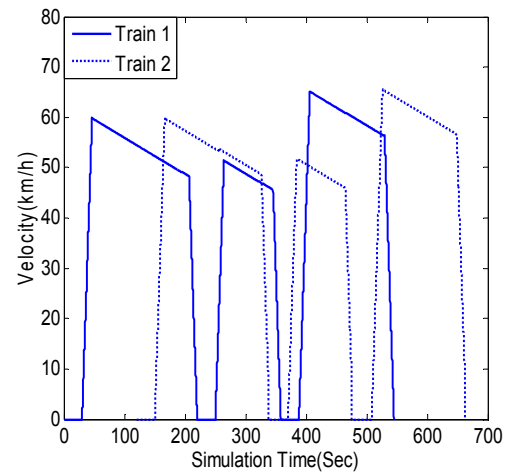

(a) Speed profile without adjustment

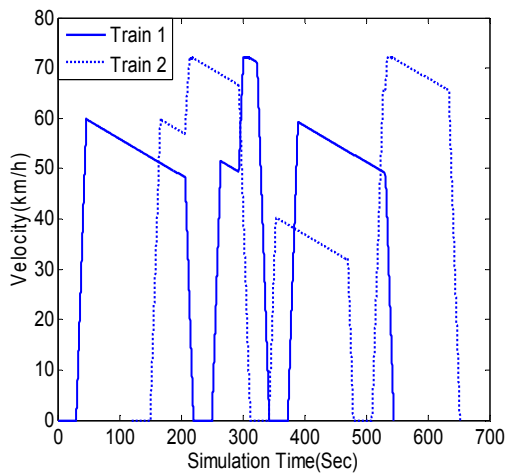

(b) Speed profile with adjustment

Figure 8: Comparison of speed profile.

Table 2: Comparison of energy consumption.

\begin{tabular}{|c|c|c|c|c|c|}
\hline \multicolumn{2}{|c|}{} & $\begin{array}{c}\text { Songjiazhuang } \\
\text {-Xiaocun }\end{array}$ & $\begin{array}{c}\text { Xiaocun- } \\
\text { Xiaohongmen }\end{array}$ & $\begin{array}{c}\text { Xiaohongmen } \\
\text {-Jiugong }\end{array}$ \\
\hline \multirow{2}{*}{$\begin{array}{c}\text { Running time between } \\
\text { stations(s) }\end{array}$} & Without adjustment & 190 & 108 & 157 \\
\cline { 2 - 6 } & \multirow{2}{*}{$\begin{array}{c}\text { With } \\
\text { adjustment }\end{array}$} & Train 1 & 190 & 93 & 172 \\
\cline { 2 - 6 } & Train 2 & 162 & 136 & 143 \\
\hline \multirow{2}{*}{$\begin{array}{c}\text { Energy consumption } \\
\text { for traction (kw.h) }\end{array}$} & Without adjustment & 22.81 & 14.64 & 31.81 \\
\cline { 2 - 6 } & \multirow{2}{*}{$\begin{array}{c}\text { With } \\
\text { adjustment }\end{array}$} & Train 1 & 22.81 & 14.66 & 27.21 \\
\cline { 2 - 6 } & Train 2 & 22.81 & 9.07 & 31.80 \\
\hline
\end{tabular}


Energy consumption for traction is the total energy needed by train to accelerate according to the objective speed profile, while total energy consumption represents energy provided by substation.

In Table 2, when Train 1 is braking, the second train 2 is coasting from Songjiazhuang to Xiaocun. Train 2 meets the conditions to accelerate. So Train 2 accelerates to absorb the regenerative braking energy. As a result, Train 2's actual running time in this inter-station reduces to $162 \mathrm{~s}$. The total energy consumption is the same with that of without adjustment just because energy consumption of this period is provided by regenerative braking energy. The Train 2 arrives at Xiaocun in advance by $28 \mathrm{~s}$.

In the same way, Train 1 arrives at Xiaohongmen in advance by $15 \mathrm{~s}$. As a result, traction energy consumption of the two trains reduces by $5.57 \mathrm{kw} . \mathrm{h}$ from Xiaocun to Xiaohongmen and $4.60 \mathrm{kw} . \mathrm{h}$ from Xiaohongmen to Jiugong, respectively, just because the arrival at last station in advance. To sum up, it saves $10.17 \mathrm{kw} . \mathrm{h}$, or $7.34 \%$ on energy consumption after using the proposed algorithm for two trains running from Songjiazhuang to Jiugong.

\subsection{Punctuality rate}

The punctuality rate is the evaluation index of the operation quality. The punctual train means the train whose difference between actual arrival time and the scheduled arrival time at the terminal station does not exceed the specified time limit. To reduce the impact of adjustment on the operational quality, the proposed model will adjust the running time between stations in real time.

Table 3: Arrival time at the terminal station.

\begin{tabular}{|c|c|c|c|c|c|}
\hline Train ID & $\mathbf{1}$ & $\mathbf{2}$ & $\mathbf{3}$ & $\mathbf{4}$ & $\mathbf{5}$ \\
\hline scheduled arrival time & $08: 36: 12$ & $08: 38: 12$ & $08: 40: 12$ & $08: 42: 12$ & $08: 44: 12$ \\
\hline actual arrival time & $08: 40: 15$ & $08: 37: 44$ & $08: 40: 04$ & $08: 41: 33$ & $08: 44: 01$ \\
\hline Difference(s) & 27 & 28 & 8 & 39 & 11 \\
\hline Train ID & $\mathbf{6}$ & $\mathbf{7}$ & $\mathbf{8}$ & $\mathbf{9}$ & $\mathbf{1 0}$ \\
\hline scheduled arrival time & $08: 46: 12$ & $08: 48: 12$ & $08: 50: 12$ & $08: 54: 12$ & $08: 56: 12$ \\
\hline actual arrival time & $08: 45: 50$ & $08: 47: 39$ & $08: 49: 15$ & $08: 53: 40$ & $08: 56: 12$ \\
\hline Difference(s) & 22 & 33 & 57 & 32 & 0 \\
\hline
\end{tabular}

Table 3 shows 10 trains' actual arrival time and the scheduled arrival time at the terminal station. The first train departures the first station at 8 o'clock. In Beijing subway, the regulation to judge a train is punctual or not is that: If difference between actual arrival time and the scheduled arrival time at the terminal station is within 1 minute, the train is punctual. 10 trains above are all punctual trains according to the regulation.

\section{Conclusion}

In this paper, an improved model is proposed by integrating train operation control and traction power supply. The integration takes the characteristics of the traction power supply, which makes the model more realistic. The accuracy of the model 
is verified based on the field test data. Based on the model, an energy-saving optimal algorithm is proposed by adjusting train's speed profile if it meets conditions to use regenerative braking energy when another train is braking. Its energy-saving effect is analyzed by simulation. The simulation results shows that, after using the proposed algorithm, traction energy consumption for a train running from Songjiazhuang to Xiaocun can be saved for 7.34\%. This effect is obtained by two improvements on the original method: one is the use of train cruising; another is the maximum of the use of regenerative energy from train's braking.

Until now the proposed model only considers the impact of third-rail voltage on the usage of regenerative energy while the transmission loss of regenerative energy is not considered. We need a more detailed model to take it into account.

\section{Acknowledgements}

The authors want to thank Mr. Yang Xin, Wang Hong-Wei and Miss Jia Zhao-Xin for their discussions. This work was partly supported by Beijing Laboratory of Urban Rail Transit, Beijing Jiaotong University (Contract No. 2013JBM121), the National High Technology Research and Development Program of China ('863' Program) No. 2011AA110502, and the PhD Programs Foundation of Ministry of Education of China (20130009120035).

\section{References}

[1] RTS 2012 The future railway, RSSB ON BEHALF OF TSLG, 2011.

[2] Gordon S. P., Lehrer D. G., Coordinated train control and energy management control strategies. Proceeding of the 1998 ASME/IEEE Joint railroad conference, pp. 165-176, 1998.

[3] Nag B., Pal M. N., Optimal design of timetables to maximize schedule reliability and minimize energy consumption, rolling stock and crew deployment. UIC Railway Energy Efficiency Conference, Paris, France, Feb. 2004.

[4] Yang, X., Li, X., Gao, Z.Y., Wang, H.W. and Tang, T., A cooperative scheduling model for timetable optimization in subway systems, IEEE Transactions on Intelligent Transportation Systems, 1(14), pp. 438-447, 2013.

[5] Yang, X., Ning, B., Li, X. and Tang, T., A Two-objective Timetable Optimization Model in Subway Systems, IEEE Transactions on Intelligent Transportation System, DOI: 10.1109/TITS.2014.2303146.

[6] Xun, J., Yang, X., Ning, B., Tang, T., Wang, W., Coordinated train control in a fully automatic operation system for reducing energy consumption. Computers in Railways XIII, WIT Press, pp. 3-13, 2012.

[7] T. Albrecht, Reducing power peaks and energy consumption in rail transit systems by simultaneous train running time control. Computers in Railways IX, WIT Press, pp. 885-894, 2004.

[8] Howlett P.G. and Pudney P.J., Energy-efficient train control, In Advances in industrial control, London, Springer, 1995.

[9] Howlett P.G., An optimal strategy for the control of a train, Journal of the Australian Mathematical Society, Series B, 4(31), pp. 454-471, 1990. 